\title{
Pore- and Micro-structural Characterization of a Novel Structural Binder based on Iron Carbonation
}

\author{
Sumanta Das ${ }^{1}$, David Stone ${ }^{2}$, Diana Convey ${ }^{3}$, Narayanan Neithalath ${ }^{4}$ \\ ${ }^{1}$ Graduate Student, School of Sustainable Engineering and the Built Environment, Arizona State \\ University, Tempe, AZ, USA, e-mail: Sumanta.Das@asu.edu \\ ${ }^{2}$ CEO, Iron Shell LLC, Tucson, AZ, USA, e-mail: dajstone@gmail.com \\ ${ }^{3}$ Principal Materials Engineer, LeRoy Eyring Center for Solid State Science, Arizona State University, \\ Tempe, AZ, USA, e-mail: Diana.Convey@asu.edu \\ ${ }^{4}$ Associate professor, School of Sustainable Engineering and the Built Environment, Arizona State \\ University, Tempe, AZ, USA, e-mail: Narayanan.Neithalath@asu.edu
}

\begin{abstract}
The pore- and micro-structural features of a novel binding material based on the carbonation of waste metallic iron powder is reported in this paper. The binder contains metallic iron powder as the major ingredient, followed by additives containing silica and alumina to facilitate favorable reaction product formation. Compressive strengths sufficient for a majority of concrete applications are attained. The material pore structure is investigated primarily through mercury intrusion porosimetry whereas electron microscopy is used for microstructural characterization. Reduction in the overall porosity and the average pore size with an increase in carbonation duration from 1 day to 4 days are noticed. The pore structure features are used in predictive models for gas and moisture transport (water vapor diffusivity and moisture permeability) through the porous medium which dictates its long-term durability when used in structural applications. Comparisons of the pore structure with those of a Portland cement paste are also provided. The morphology of the reaction products in the iron-based binder, its elemental composition and the distribution of constituent elements in the microstructure are also reported.
\end{abstract}

Keywords: Iron powder, Carbonation, Porosity, Diffusivity, Permeability, Microstructure 


\subsection{INTRODUCTION}

Anthropogenic emission of $\mathrm{CO}_{2}$ is accepted as being responsible for changes in global climate and it has potentially irreversible damaging impacts on ecosystems and societies. Numerous studies have been published in the past on sequestering $\mathrm{CO}_{2}$ [1-7] along with different direct and indirect methods of reducing the overall $\mathrm{CO}_{2}$ emissions. Among the $\mathrm{CO}_{2}$ sequestration methods, mineral route of carbonation, especially of alkaline earth oxide bearing rocks, has proven to be an effective means $[4,8-$ 13]. The high compressive and tensile strength of secondary carbonate rocks [14-16], formed as a result of mineral trapping, suggests the possibility of using mineral carbonation to form a sustainable binder for construction.

In the quest to carbonate other metal or alkali metal species which are abundantly available as waste/by-product materials, the authors carried out a detailed study [17] on the potential of waste metallic iron powder to be carbonated into a useful structural binder material akin to Portland cement paste. It was found that the mechanical properties comparable to conventional cementitious systems can be obtained through proper proportioning and curing methods. Significant amounts of waste iron powder as baghouse dust is produced during the Electric Arc Furnace (EAF) manufacturing process of steel and from the shot blasting operations of structural steel sections. This material is generally landfilled because the recycling process is difficult and not cost-effective. It has been reported that $\mathrm{CO}_{2}$ corrosion of steel pipelines used to carry oil and gas results in carbonate scales that adhere strongly to the parent material [18-21]. The iron-based binder developed here, which can be used in lieu of ordinary Portland cement (OPC) for concrete construction, provides synergistic benefits through the incorporation of $\mathrm{CO}_{2}$ emitted from an industrial operation as well as the reduction of OPC (the production of which contributes greatly to $\mathrm{CO}_{2}$ emissions).

In the authors' recent work on iron powder carbonation [17], the effect of source materials (including minor ingredients) on the compressive strength and extent of reaction product formation were investigated in detail. The study reported in this paper investigates the pore structure and microstructure of the iron-based binder. The pore structure of the iron-based binder is characterized in detail using mercury intrusion porosimetry (MIP). The pore structure features extracted using MIP are used in established theoretical models to predict the gas diffusivity and moisture permeability of these novel binders. Electron microscopy coupled with energy-dispersive X-ray spectroscopy (EDS) is used to evaluate the morphology of the reaction products and the chemical constituents of the microstructure. Thus this paper sheds light on the pore- and micro-structure of iron-based binder systems and provides 
valuable information that is critical towards positioning this material as a potential alternative to OPC systems, especially in regions where the requisite source materials and $\mathrm{CO}_{2}$-emitting processes are present.

\subsection{EXPERIMENTAL PROGRAM}

\subsection{Starting Materials: Composition and Particle Sizes}

Metallic iron powder with a median particle size of $19.03 \mu \mathrm{m}$ is used as the main starting material in this study. This material is the waste generated from structural steel fabrication, which is otherwise landfilled at great cost. The iron powder consists of $88 \% \mathrm{Fe}$ and $10 \%$ Oxygen (due to some amount of atmospheric oxidation) along with trace quantities of $\mathrm{Cu}, \mathrm{Mn}$, and $\mathrm{Ca}$. The iron powder is elongated and angular in shape as can be seen from Figure 1, thereby influencing the rheological properties of the mixture. However, the larger surface area-to-volume ratio of this shape provides benefits related to reactivity.

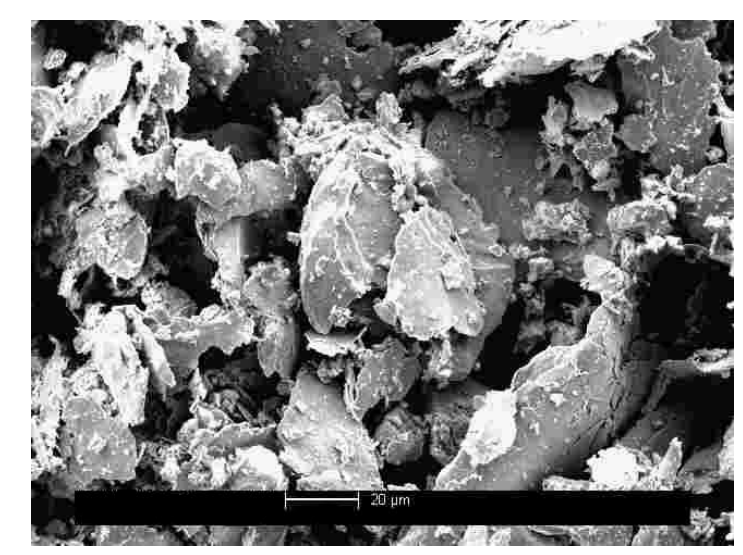

Figure 1: SEM image of iron particles. The scale bar corresponds to $20 \mu \mathrm{m}$.

In addition to the iron powder, the minor ingredients used in binder synthesis include Class $\mathrm{F}$ fly ash and metakaolin conforming to ASTM C 618, and limestone powder (median particle size of $0.7 \mu \mathrm{m}$ ) conforming to ASTM C 568. Fly ash was used to provide a silica source for the reactions (to potentially facilitate iron silicate complexation [22,23]), while the fine limestone powder provides nucleation sites and metakaolin provides cohesiveness to the paste mixtures [17]. In the process of iron carbonation, water is only a mediator in the reactions which serves as an agent of mass-transfer and does not as such chemically participate in the reactions. Minimization of water demand, yet keeping the consistency and cohesiveness of the mixture, was achieved through the use of metakaolin. An organic reducing 
agent/chelating agent for metal cations, which is a weak acid (oxalic acid in this case), was also used to enhance iron dissolution and to prevent oxidation. Commercially available Type I/II ordinary Portland cement (OPC) conforming to ASTM C 150 was used to prepare conventional cement pastes to ensure comparisons of the pore structure of the novel iron-based binder systems with those of the traditional OPC-based systems. The chemical compositions of OPC, fly ash and metakaolin are tabulated in Table 1.

Table 1: Chemical composition of OPC and minor component materials for iron carbonate synthesis

\begin{tabular}{cccc}
\hline $\begin{array}{c}\text { Components } \\
(\%)\end{array}$ & Cement & Fly ash & Metakaolin \\
\hline $\mathrm{SiO}_{2}$ & 21.0 & 59.52 & 51.7 \\
$\mathrm{Al}_{2} \mathrm{O}_{3}$ & 3.61 & 23.03 & 43.2 \\
$\mathrm{Fe}_{2} \mathrm{O}_{3}$ & 3.47 & 4.62 & 0.5 \\
$\mathrm{CaO}$ & 63.0 & 4.87 & - \\
$\mathrm{MgO}$ & 3.26 & - & - \\
$\mathrm{SO}_{3}$ & 3.04 & 0.48 & - \\
$\mathrm{Na}_{2} \mathrm{O}$ & 0.16 & 2.32 & - \\
$\mathrm{K}_{2} \mathrm{O}$ & 0.36 & - & - \\
$\mathrm{LOI}$ & 2.13 & 0.37 & 0.16 \\
\hline
\end{tabular}

The particle size distributions of the iron powder, fly ash, metakaolin, limestone powder and OPC are shown in Figure 2. All the ingredients are finer than the iron powder used. Please note that the quantified data presented in this paper could vary based on iron powder fineness. However, the general mechanisms and trends are expected to remain the same.

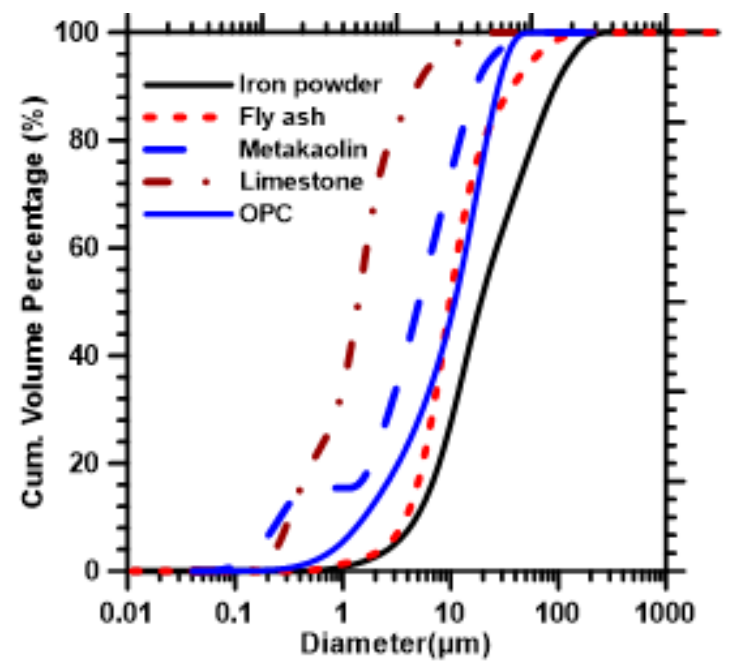

Figure 2. Particle size distribution of metallic iron powder, OPC, fly ash, metakaolin and limestone powder. 


\subsection{Mixing Procedure and Determination of Optimal Mixture Proportions}

The mixing procedure involves initial dry mixing of all materials (iron powder, fly ash, limestone powder, metakaolin and the organic reducing agent). Water was then added and mixed in order to obtain a uniform cohesive mixture. The mass-based water-to-solids ratio $(\mathrm{w} / \mathrm{s})$ was varied between 0.22 and 0.25 depending upon the proportions of the constituents of the mixtures to attain a cohesive mix. Since the carbonation process of iron does not incorporate water in the reaction products and it is merely an agent of mass-transfer, the w/s used is primarily based on the criteria of obtaining desired workability, and ability to strip the molds without specimen breakage. Cylindrical samples of $32.5 \mathrm{~mm}$ diameter and $65 \mathrm{~mm}$ length were prepared using a Harvard miniature compaction apparatus (ASTM D 4609 - Annex A1). The specimens were demolded immediately after compaction using the specimen ejector. Next, they were placed inside clear plastic bags filled with $100 \% \mathrm{CO}_{2}$ at room temperature inside a fume hood for 1 to 4 days. The bags were refilled with $\mathrm{CO}_{2}$ every 12 hours or so to maintain saturation inside the chamber. After the respective durations of $\mathrm{CO}_{2}$ exposure, the samples were placed in air at room temperature to allow the moisture to evaporate for 1 to 30 days. The water-to-cementitious materials ratio $(w / c m)$ adopted for the OPC-based mixture used for the pore structure studies was 0.40 , which is common for moderate-strength concretes in many infrastructural applications.

A total of eight different mixtures with varying iron powder, fly ash, limestone, and metakaolin contents were proportioned after trials with many other mixture combinations. The iron powder content ranged from 58 to $69 \%$ by mass whereas fly ash, limestone and metakaolin contents varied in the range of 15 20, $8-10$ and $6-10 \%$ by mass respectively. The proportions of the eight mixtures are shown in Table 2. The performance of these mixtures has been reported in detail in [17].

Table 2. Mixture proportions for the preliminary study

\begin{tabular}{|c|c|c|c|c|c|c|c|c|}
\hline \multirow{2}{*}{ Component materials } & \multicolumn{8}{|c|}{ \% by mass of the total powder } \\
\cline { 2 - 11 } & \multicolumn{8}{|c|}{ Mixture number } \\
\cline { 2 - 11 } & 1 & 2 & 3 & 4 & 5 & 6 & 7 & 8 \\
\hline Iron powder & 64 & 60 & 62 & 58 & 69 & 65 & 67 & 63 \\
\hline Fly ash & 20 & 20 & 20 & 20 & 15 & 15 & 15 & 15 \\
\hline Limestone & 8 & 8 & 10 & 10 & 8 & 8 & 10 & 10 \\
\hline Metakaolin & 6 & 10 & 6 & 10 & 6 & 10 & 6 & 10 \\
\hline
\end{tabular}

These proportions were chosen such that they were able to be compacted into molds to create a homogeneous mixture and able to be demolded without breakage. In all cases, the organic reducing agent was added in powder form at $2 \%$ of the total mass of the constituents. In order to obtain the 
mixture with the best mechanical performance, the specimens were kept in the $\mathrm{CO}_{2}$ atmosphere immediately after removal from the molds (typically 5 minutes after casting) for 3 days, and then cured in air for 2 days before they were tested in uniaxial compression. The best performing mixture contained $60 \%$ iron powder, 20\% fly ash, $8 \%$ limestone, and 10\% metakaolin (Mixture number 2 in Table 2). Subsequent studies showed that four days curing in a $\mathrm{CO}_{2}$ environment followed by 3 days of airexposure resulted in the highest compressive strength [17].

\subsection{Pore Structure Determination using MIP}

Mercury intrusion porosimetry (MIP) which is a well-established technique to investigate the pore structure of porous materials, was adopted here to study the pore structure of iron carbonate systems. The samples for MIP were taken from the same core of the cylindrical sample prepared for compressive strength testing. Thermal analysis results had shown that the selected $\mathrm{CO}_{2}$ exposure duration resulted in similar carbonation levels in the core of the $32.5 \mathrm{~mm}$ diameter sample as that of the surface [17]. MIP was performed in two steps: (i) evacuation of gases, filling the sample holder with mercury and increasing the pressure to $345 \mathrm{kPa}$, and (ii) intrusion of the mercury into the sample at high pressures (up to $414 \mathrm{MPa}$ ). The contact angle and surface tension used for the analysis were $130^{\circ}$ and $0.485 \mathrm{~N} / \mathrm{m}$ respectively. Accurate determination of the contact angle was not carried out in this study, which could have introduced errors in the pore size determination. However, since the emphasis is on comparative evaluation of pore sizes, this inaccuracy is not deemed to be critical. The pore diameters can be evaluated using Washburn equation, based on the assumption that the pores in the porous media are cylindrical in shape [24-26]. A minimum pore diameter of $0.003 \mu \mathrm{m}$ can be evaluated using MIP. Total volume of mercury intruded (which is the total porosity) and critical pore diameter (which is the peak in the differential volume intruded curve) can be obtained from MIP. The average pore diameter $\left(d_{a}\right)$ is calculated from the total pore volume and the pore surface areas as: [24]

$$
d_{a}=\frac{4 V}{A}
$$

where $V$ is the volume of mercury intruded per gram of sample $(\mathrm{cc} / \mathrm{g})$ and $A$ is the total pore area $\left(\mathrm{m}^{2} / \mathrm{g}\right)$ obtained from MIP. The pore tortuosity $(\tau)$ was empirically determined from the pore volume $(\phi)$ as [27]:

$$
\tau=2.23-1.13 \phi \text { for } 0.05 \leq \phi \leq 0.95
$$




\subsection{Microstructural Evaluation}

Morphological and compositional analyses of the iron-based binder systems were carried out using a Philips XL30 Field Emission Environmental scanning electron microscope (FESEM) coupled with energy dispersive X-ray spectroscope (EDS). The pastes were crushed and small pieces from the core were mounted to the stub with epoxy resin for FESEM. While secondary electron (SE) imaging techniques are useful to examine the morphology of the fractured surfaces, the roughness of these surfaces can introduce errors when attempting to quantify the microstructure. Therefore, a suitable combination of grinding and polishing is required to achieve a level of flatness appropriate for microstructural and compositional analysis.

Prior to polishing, the sample was ultrasonically cleaned, rinsed with ethyl alcohol and dried to remove debris from sectioning/handling. The sample was then encapsulated using a 2-part epoxy and vacuum impregnated at $95 \mathrm{kPa}$ followed by an overnight cure at room temperature. Coarse grinding steps were accomplished using silicon carbide ( $\mathrm{SiC}$ ) abrasive discs to planarize and remove deformations caused by sectioning. Successive polishing steps were carried out using smaller sized abrasives, and completed using $0.04 \mu \mathrm{m}$ colloidal silica suspension. The polished sample was then imaged and evaluated using a JEOL JXA-8530F Hyperprobe. This electron probe microanalyzer (EPMA) features a field emission electron gun, five Wavelength Dispersive Spectrometers (WDS) and EDS.

\subsection{RESULTS AND DISCUSSIONS}

\subsection{Compressive Strength of Iron Carbonate Binders}

The eight different mixtures listed in Table 2 were proportioned to understand the effects of the various constituents on the compressive strength of iron carbonate binders. The primary goal was to determine the optimal mixture which resulted in the highest compressive strength after a specific curing regime was implemented. The samples were kept in a $100 \% \mathrm{CO}_{2}$ environment for 3 days and then exposed to air for 2 days at $23 \pm 2^{\circ} \mathrm{C}$ and a $\mathrm{RH}$ of $30 \%$. The resulting compressive strength of these mixtures is reported in Figure 3. Mixtures 1 and 2 were found to be the two best performing mixtures. The reasons attributed to the improved performance of these mixtures are described in detail in [17]. Mixture 2 is used for the detailed pore- and micro-structural characterization studies reported in the following results. 


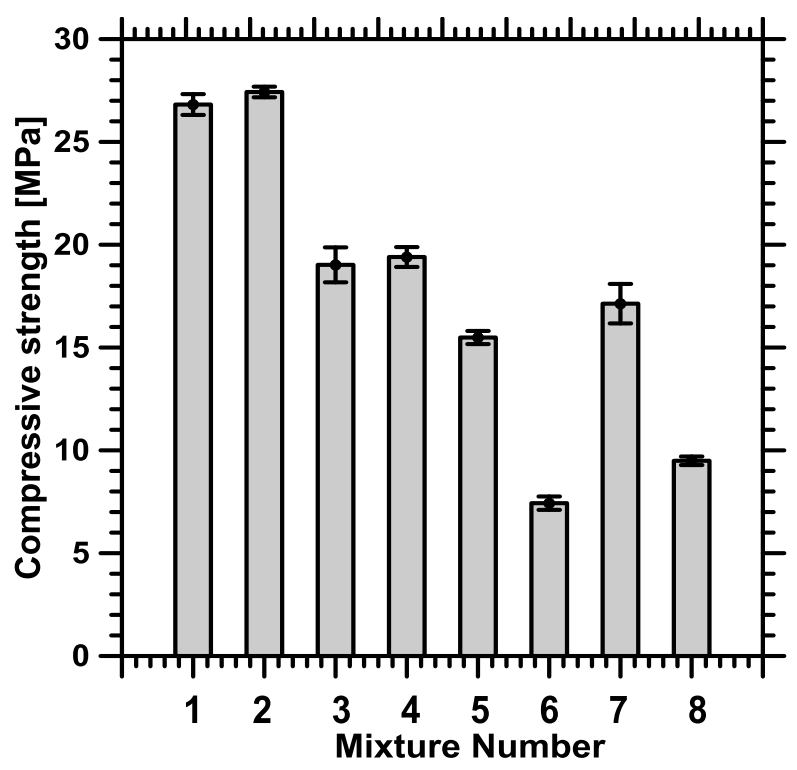

Figure 3: Compressive strengths of the iron carbonate mixtures listed in Table 2 (exposure condition: 3 days in $\mathrm{CO}_{2}$ and 2 days in air)

Figure $4(a)$ shows the development of the compressive strength of Mixture 2 with increasing carbonation duration. Longer carbonation durations result in a decrease in the total pore volume (quantified later) due to increased reaction product formation. The effect of air-exposure time on the compressive strength is shown in Figure $4(\mathrm{~b})$. The samples were cured in $\mathrm{CO}_{2}$ for four days prior to exposing them to air at $23 \pm 2^{\circ} \mathrm{C}$ and $15 \% \mathrm{RH}$ for varying durations. The results suggest the compressive strength increases in the first three days of air-exposure due to loss of evaporable moisture from the sample [17] and remains unchanged thereafter.
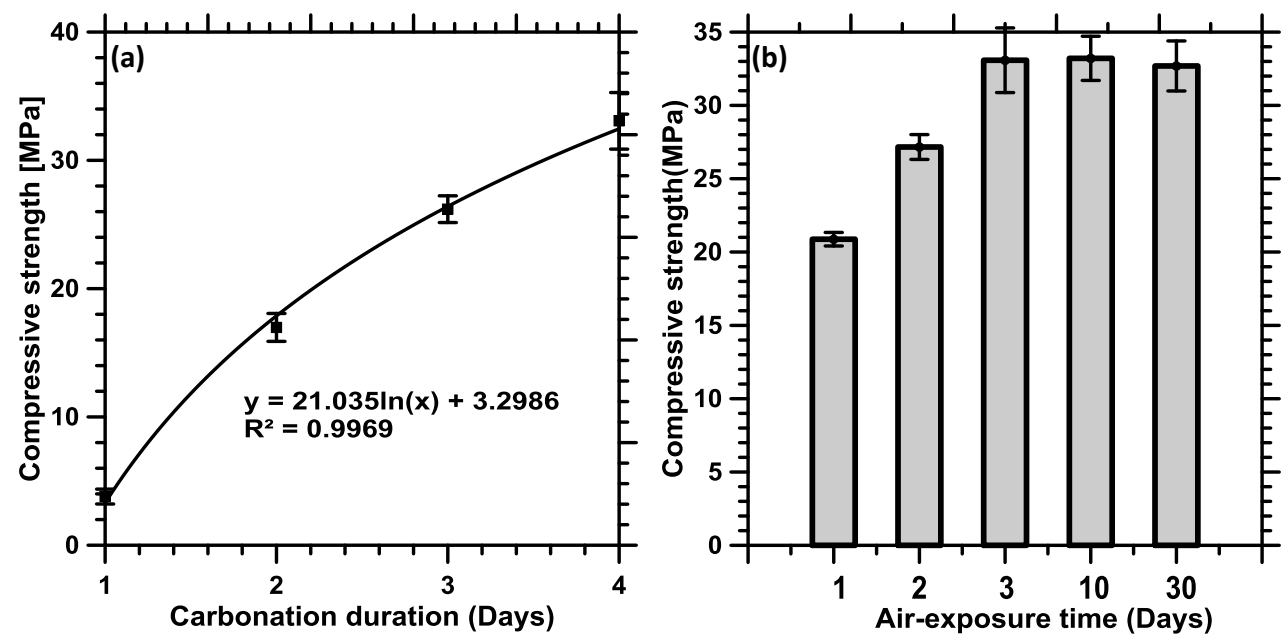

Figure 4: Variation of compressive strength of Mixture 2 (60\% iron powder, $20 \%$ fly ash, $8 \%$ limestone, $10 \%$ metakaolin) as a function of: (a) varying carbonation duration, and (b) varying air-exposure duration after 4 days of carbonation. 


\subsection{Pore-Structural Analysis of Iron-Based Binders}

This section examines the pore structure of the iron carbonate binders. It is well known that the pore structural features exert a significant influence on the mechanical and transport properties [28,29], of any porous material. The influences of source material composition and treatment conditions (carbonation and air-exposure durations) on the resultant pore structure are discussed.

\subsubsection{Effect of Starting Material Composition}

Mixture 2 (From Table 2) was the best-performing mixture from a compressive strength standpoint, while Mixture 6 performed the worst as shown in Figure 3. A comparison of the pore structure of these two mixtures as determined using MIP is shown in Figure 5. There is a significant difference in the total volume of mercury intruded, with Mixture 2, showing a pore volume of about half as that of Mixture 6, implying a denser microstructure in the former mixture. The critical pore size, which is indicated by the peak location in the derivative of the pore size-volume intruded curve, remains generally invariant between the two mixtures. A companion study has confirmed through thermo-gravimetric analysis that the carbonation efficiency and the amounts of reaction products formed in Mixture 6 was much lower as compared to Mixture 2 and, that the carbonation efficiency and mechanical properties of iron carbonate binders are very sensitive to the overall starting material composition [17].

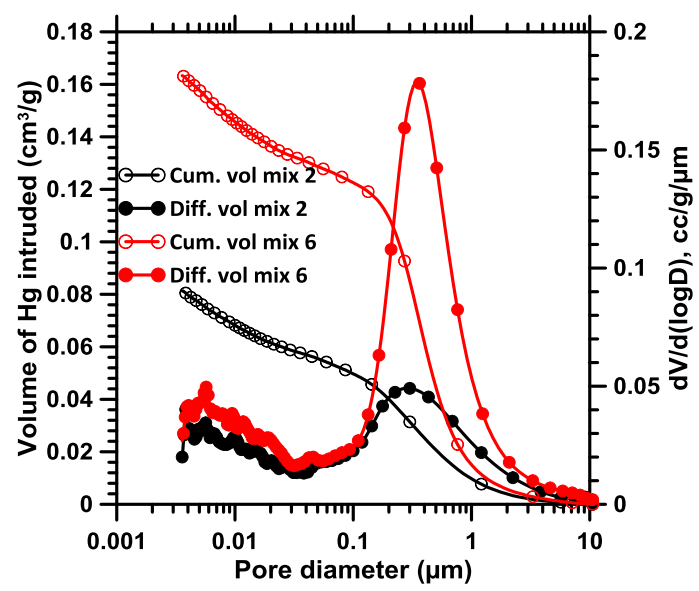

Figure 5: Comparison of pore structure of Mixtures 2 (60\% iron powder, $20 \%$ fly ash, $8 \%$ limestone, $10 \%$ metakaolin) and 6 (65\% iron powder, $15 \%$ fly ash, $8 \%$ limestone, $10 \%$ metakaolin) after 4 days of carbonation and 3 days of air-exposure. 


\subsubsection{Effect of Carbonation and Air-Exposure Duration}

The volume of mercury intruded as a function of the pore sizes and the derivative of this relationship are shown in Figure 6 for various carbonation regimes applied to Mixture 2. For all the carbonation durations, an air-exposure duration of 3 days following carbonation was chosen as there is no appreciable increase in compressive strength beyond this air-exposure duration as shown in Figure 4 (b). The total volume of mercury intruded reduces significantly with an increase in carbonation duration due to the increased formation of reaction products [17]. The consequent increase in specimen density results in improved mechanical properties. The derivative plots show no significant differences in the peak locations as a function of the carbonation duration. However, the reduction in porosity with increasing carbonation duration can be expected to reduce the number of pores of the critical size (the size corresponding to the major peak in the derivative curve). Therefore, while the critical pore sizes remain rather unchanged, the average pore size is reduced considerably with an increase in the carbonation duration. The reduction in the total pore volume is known to primarily influence the mechanical properties, whereas, the reduction in pore size is more influential in transport properties.
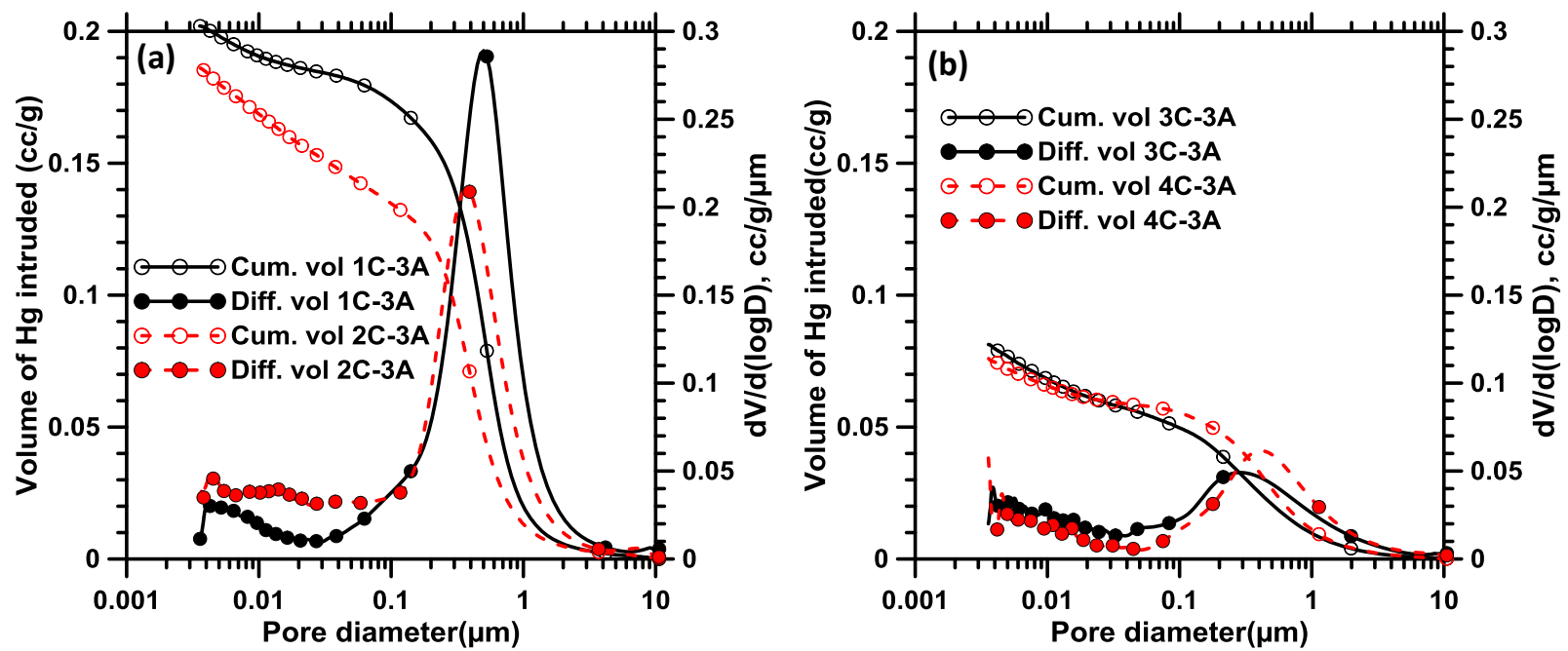

Figure 6: Effect of carbonation duration on pore structure for Mixture 2. Carbonation duration of: (a) 1 day and 2 days; (b) 3 days and 4 days. Air exposure of 3 days after all carbonation regimes. The number before ' $C$ ' represents the days of carbonation whereas the number before ' $A$ ' represents the air-

exposure time in days. 
Figure 7 (a) depicts the carbonation efficiency as a function of $\mathrm{CO}_{2}$ exposure time in relation to pore size and the representative range of sizes as determined using MIP. The percentage of pores of three different size ranges determined using the Washburn equation is shown here. Even though the size range determination using MIP is somewhat flawed, it is useful to compare between materials of similar chemical composition and processed in a similar fashion [30-33]. The fraction of pores greater than 0.2 $\mu \mathrm{m}$ (the larger pores, which are unfilled owing to insufficient reaction product formation) decreases with increasing carbonation period whereas the fraction of pores in the range $0.0036-0.05 \mu \mathrm{m}$ increases correspondingly. For example, after 1 day of carbonation, the pores $>0.2 \mu \mathrm{m}$ constitute more than $70 \%$ of the overall pore volume. After 4 days of carbonation, this fraction drops to approximately $45 \%$. The smaller pores are likely to be the ones which are part of the reaction product structure. Their relative increase represents an increase in product formation with carbonation as the thermal analysis [17] and mechanical property results suggest. Also, the trends in the pore sizes depicted in Figure 7 follow the trends in compressive strength, thereby lending credibility to the use of this method.
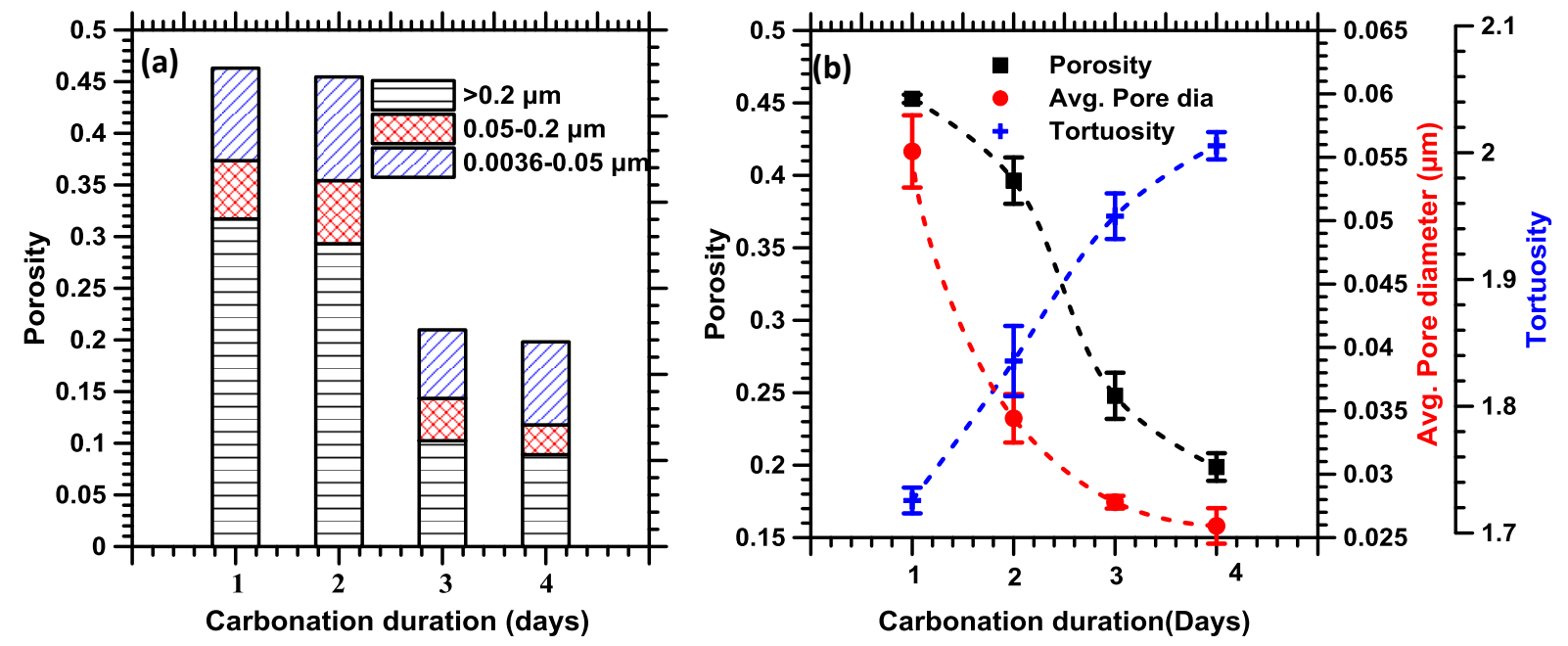

Figure 7: (a) Pore size ranges in iron carbonate binder (Mixture 2) as a function of carbonation duration; and (b) variation of porosity, pore sizes, and tortuosity as a function of carbonation duration. Air exposure duration of 3 days after respective carbonation durations

Figure $7(b)$ depicts the variation of porosity, average pore diameter (calculated using Equation 1) and tortuosity (calculated using Equation 2) with varying carbonation durations. As seen in this figure, both porosity and average pore diameter decrease significantly when the carbonation duration is increased from 1 to 4 days. These observations are in agreement with the compressive strength results in Figure 4(a) and the thermogravimetric analysis results described in [17]. With an increase in the carbonation duration, the pore structure becomes more tortuous due to increased amounts of reaction product 
formation. The porosity and tortuosity values presented here are used to calculate the theoretical transport parameters of iron carbonate systems which are presented later in this paper.

\subsection{Comparison of the Pore Structures of Iron Carbonate and OPC-based Systems}

In this section, a comparison of the overall pore volumes and the critical pore size of iron carbonate and OPC binder systems is described. Figure 8(a) shows that the porosity of the hardened OPC paste (cured in moisture for 28 days) is higher as compared to the iron-based binder (carbonated for 4 days, followed by air-exposure for 3 days). However, one should be aware of the fact that the porosity of OPC systems can be controlled through several means such as reduction in water-to-cementing materials ratio $(w / c m)$ facilitated by the use of chemical admixtures, incorporation of other reactive ingredients and improved curing practices. The pore structure of OPC pastes provided here is only used as a point of comparison and not intended to derive quantitative conclusions regarding the pore structure of OPC systems, which can be found in several other publications [34-37]. Also, for the iron-based binder systems, the composition and curing conditions used are designed to provide the optimal microstructure and strength. From the derivative plots shown in Figure 8(a), it is clear that the ironbased binder has a larger critical pore diameter than the OPC system which will impact the transport of moisture, ions, and gases through the pore structure. The increased pore size is likely a result of the $\mathrm{H}_{2}$ gas which is a by-product of iron carbonation. The pore volume of the OPC paste corresponding to a pore diameter range of 0.0036-0.05 $\mu \mathrm{m}$ (smallest pores) is higher than that for the iron-based binder as shown in Figure $8(\mathrm{~b})$. Since the pores of this range are generally observed as part of the reaction product, this implies a larger amount of reaction products in the OPC paste, which is unsurprising. The volume of pores corresponding to the size range of 0.05-0.2 $\mu \mathrm{m}$ is higher for the iron-based binder, whereas the amount of larger pores remains relatively the same in both these systems. The larger amount of pores in the transport-controlling pore size range $(>0.05 \mu \mathrm{m})$ in the iron carbonate binder indicates the need for studies on refining the pore structure in these novel materials. 

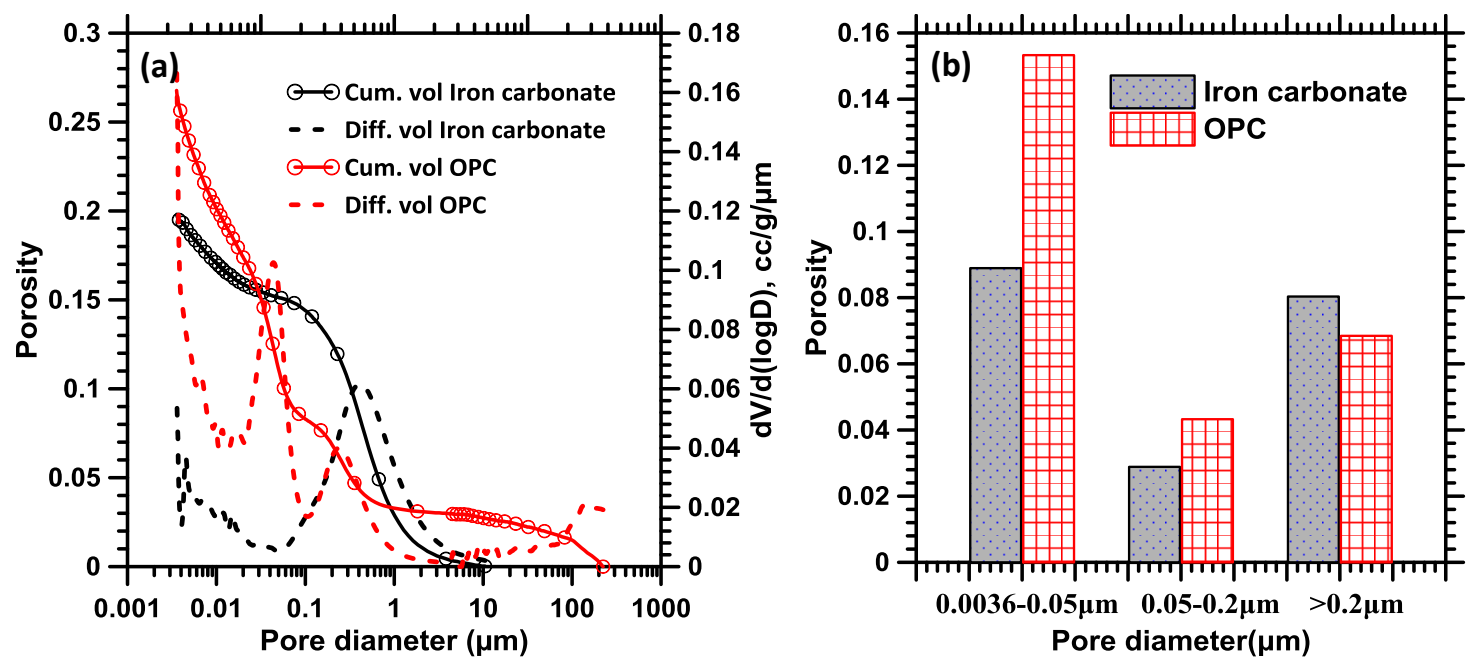

Figure 8: Comparison between the pore structures of iron carbonate and OPC paste systems: (a) porosity and the derivative volume intruded as functions of the pore diameter, and (b) pore volume fraction for different pore size ranges. For the iron carbonate binder, the data corresponds to Mixture 2 after 4 days of carbonation and 3 days of air-exposure while the OPC pastes were cured for 28 days in a moist environment.

\subsection{Extracting the Transport Characteristics of Iron-Based Binders from Pore Structure Information}

The pore structure features of the iron-based binder systems described in the previous sections are used here to obtain relative indicators of the transport performance of iron-based binders. Transport of moisture and ions (e.g., $\mathrm{Cl}^{-}$) through mechanisms such as permeability and diffusivity are important in dictating the durability of binders which have the potential to be used in infrastructural construction. The major transport descriptors extracted from the measured pore structure features in this study are water vapor diffusivity and moisture permeability.

\subsubsection{Gas diffusion and moisture permeability}

Diffusion of a gaseous phase into a porous media under steady state conditions can be expressed using Fick's first law as shown in Equation 4.

$$
F_{g}=-D_{e} \frac{\partial c}{\partial x}
$$

Here, $F_{g}$ is the diffusion flux, $D_{e}$ is the effective diffusion coefficient of gas in the porous media, $c$ is the concentration and $x$ is the distance. The normalized diffusivity $\left(D^{\prime}\right)$ is the ratio of $D_{e}$ to the gas diffusion coefficient $D_{a}$ in air. The relationship between the diffusivity and porosity is often expressed using 
Archie's law [38] as shown in Equation 5. The exponent $m$ is called the cementation factor determined experimentally by fitting the data for diffusivity and porosity. Different $\mathrm{m}$ values ranging from 1.65 to 4.89 are reported in the literature for porous media including rocks of varying morphology and pore structure [39].

$$
D^{\prime}=\frac{D_{e}}{D_{a}}=\phi^{m}
$$

Diffusion of gases in a porous media can be considered to take place primarily through one of the three mechanisms: (i) through the interconnected pore volume, (ii) through the pore surface, or (iii) through the solid matrix material [40]. In many porous media, diffusion through the pore volume is likely to be the dominant path unless the porosity and permeability are extremely low. There are two limiting cases of such a diffusion process: Knudsen diffusion and normal diffusion. In Knudsen diffusion, collision of gas molecules with the solid pore wall is the dominant mechanism whereas in normal diffusion the collision between gas molecules is limiting and the gas-wall collision is negligible [40]. Mean free transport paths determine the type of dominant diffusion mechanism. For Knudsen diffusion to be the limiting case, the mean free path needs to be greater than the average pore diameter in the media, and for normal diffusion to become dominant, the mean free path has to be smaller than the average pore diameter [40]. The diffusion coefficient of water vapor in air, $D_{a}$, is $25 \times 10^{-6} \mathrm{~m}^{2} / \mathrm{s}[41,42]$. The mean free path of water vapor $(\lambda)$ at standard temperature and pressure $\left(25^{\circ} \mathrm{C}, 1 \mathrm{bar}\right)$ is calculated as $0.12 \mu \mathrm{m}$ using the following equation $[43,44]$ :

$$
\lambda=\frac{R T}{\sqrt{2} N_{A} \pi d^{2} p}
$$

Here, $R$ is the universal gas constant, $T$ is the temperature in $K, N_{A}$ is the Avogadro constant, $d$ is the diameter of water vapor molecule $(0.275 \mathrm{~nm})$ and $p$ is the pressure. The pore structure details of iron carbonate binders from MIP from Figure 7(b) suggests that the average pore diameter for the matrices investigated here are smaller than the mean free path of water vapor. Hence, the Knudsen diffusion can be considered to be the dominant mechanism. The gas diffusion coefficient (D) can be obtained from the Knudsen diffusion coefficient $\left(D_{K A}\right)$ and diffusion coefficient in air as [40]:

$$
\frac{1}{D}=\frac{1}{D_{a}}+\frac{1}{D_{K A}}
$$


The Knudsen diffusion coefficient $\left(\mathrm{m}^{2} / \mathrm{s}\right)$ can be expresses as follows [45]:

$$
D_{K A}=48.5 d_{a} \sqrt{\frac{T}{M}}
$$

where $T$ is the absolute temperature $(K) ; M$ is the molecular weight of water $(g / m o l e)$ and $d_{a}$ is the average pore diameter $(\mu \mathrm{m})$. The effective diffusion coefficient $\left(D_{e}\right)$ can then be calculated as $[27,40,46]$ :

$$
D_{e}=\frac{\phi}{\tau} D
$$

where $\phi$ is the total volumetric porosity and $\tau$ is the tortuosity of the pore structure.

The intrinsic permeability is a measure of relative ease with which a fluid can be transported through a porous media under a potential gradient. Many studies derive permeability of a porous material from MIP data [47-50]. Among them, the Katz-Thompson model is widely used and is employed here to evaluate the intrinsic permeability of iron-based binder. For a medium with a characteristic length scale $L_{c}$, intrinsic permeability $(k)$ can be expressed as,

$$
k=\frac{1}{226}\left(\frac{\sigma_{e f f}}{\sigma_{0}}\right)\left(L_{c}\right)^{2}
$$

Here the term $\left(\sigma_{\text {eff }} / \sigma_{0}\right)$ is the normalized electrical conductivity of the medium. $(1 / 226)$ is a constant developed by Katz and Thompson for rock specimens. The Katz-Thompson theory is based on the assumption the pores are cylindrical. Previous studies have used the pore structure data (extracted from MIP or image analysis techniques) to derive the permeability of porous media $[47,48,50-52]$. Katz and Thompson simplified Equation 10 to include only characteristic length terms extractable from MIP to predict the permeability, which is given as [50]:

$$
k=\frac{1}{89}\left(L_{\max }\right)^{2}\left(\frac{L_{\max }}{L_{c}}\right) \phi S\left(L_{\max }\right)
$$

Here, $L_{c}$ is characteristic length or the pore diameter corresponding to threshold pressure (the pressure corresponding to point of inflection in the rapidly rising range of the cumulative mercury intrusion curve) $[50,53], L_{\max }$ is the pore diameter at which the hydraulic conductance is maximum; $\phi$ is the 
porosity and $S\left(L_{\max }\right)$ is the fraction of volume of connected pore space composed of pores of size $L_{\max }$ or larger.

The normalized water vapor diffusivity and moisture permeability as a function of carbonation duration is shown in Figure 9(a). With a reduction in porosity and pore sizes and a consequent increase in tortuosity as a result of increased carbonation, both the normalized diffusivity and permeability decrease as expected. The reduction in diffusivity and permeability follows the same trend as the reduction of porosity with increase in carbonation duration for the binder as shown in Figure 7. Figure 9(b) shows the normalized diffusivity-porosity relationship for the iron-based binder. The diffusivity values are calculated from the porosity data by incorporating the effective diffusion coefficient values $\left(D_{e}\right)$ (Equation 9) in Equation 5. The value of the exponent $m$ in Equation 5 is obtained as 3.18 through a non-linear regression fit to Archie's law with 95\% confidence bounds. The value of $m$ is in the realistic range of 1.6 (red brick) to 4.89 (mudstone) as reported elsewhere [39]. It has also been reported that a smaller $\mathrm{m}$ value correlates to larger pores indicating higher diffusivity due to the lower tortuosity and increased pore connectivity. The relationship between porosity and moisture permeability is shown in Figure 9(c). As expected, permeability increases as the porosity increases-note the conventional power-law permeability-porosity relationship that is seen to be valid for the iron-based binder. It should be noted that the value of permeability of the iron-based binder after 4 days of carbonation $(k=2.5 x$ $\left.10^{-16} \mathrm{~m}^{2}\right)$ is significantly higher than that of a 28-day moist-cured hardened cement paste $\left(\mathrm{k}=6.17 \times 10^{-20}\right.$ $\mathrm{m}^{2}$ ) [36]. This is primarily due to larger pore sizes in iron carbonate binders even though the total pore volumes in the iron-based binder system are lower. However, it should also be considered that the transport characteristics of concretes (containing aggregates in large volume fractions along with the binder) are more important in application scenarios. The lower volume of the paste (or the binding fraction) in concretes result in the paste properties being less dominant as compared to those where pure paste is used. 

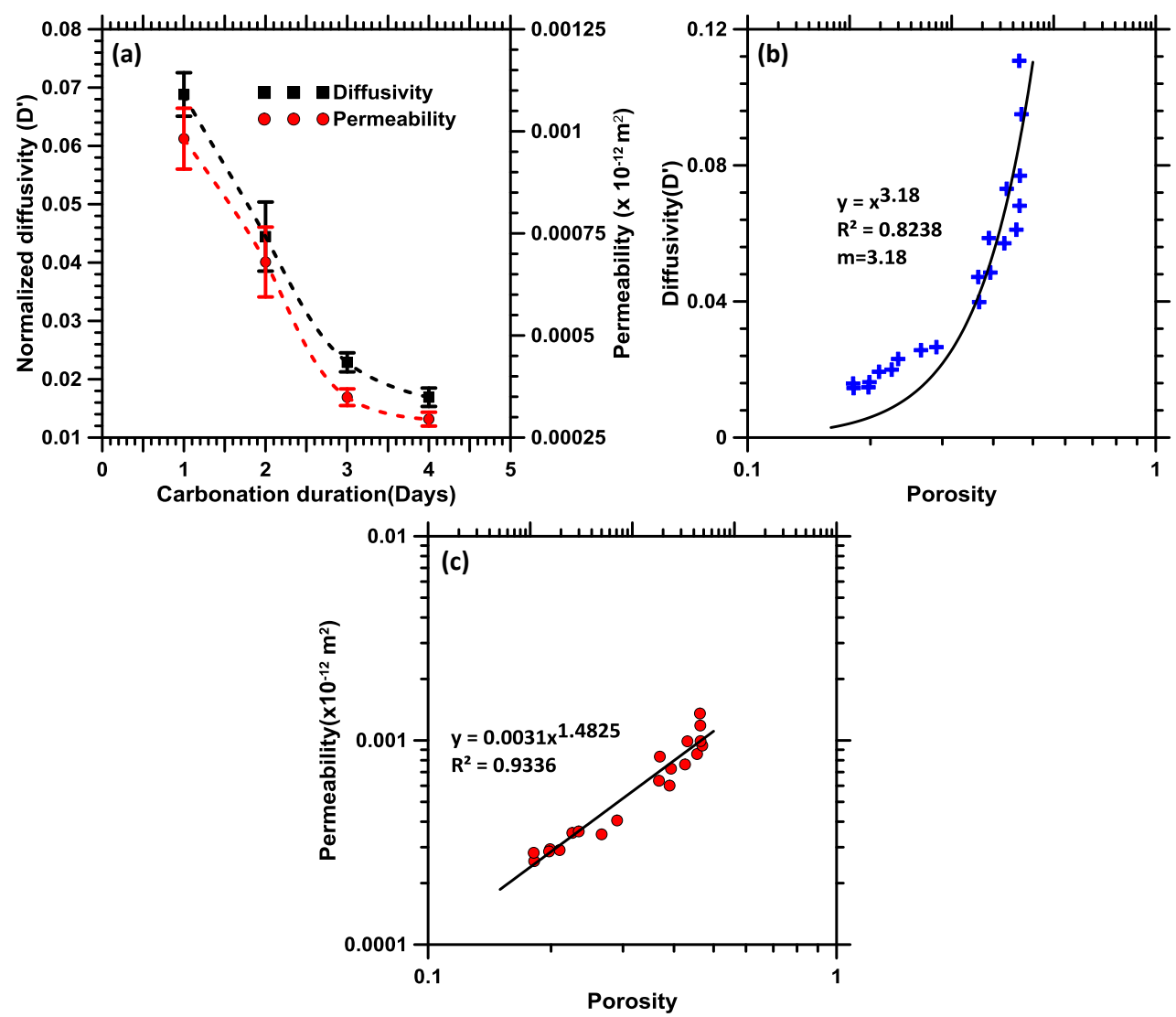

Figure 9 (a): Effect of carbonation duration on diffusivity and permeability; (b) diffusivity-porosity relationship (Archie's law); (c) permeability-porosity relationship for the iron-based binder. All the data points correspond to those of Mixture 2.

\subsection{Microstructural Evaluation}

The reaction products formed from iron carbonation and the influence of source materials have been described in detail [17]. In this paper, the morphological and compositional features of these binders are outlined. Compositional analysis using both secondary electron (SE) imaging and backscattered electron (BE) imaging is described here. There are several publications that report microstructural quantification of cementitious systems using SEM/EDS [REFS]. But, it should be noted that the main objective here is to identify the elements present in the reaction product since SEM/EDS is not suitable for accurate quantification [REFS] especially on rough surfaces. Hence, in this study the microstructural analysis is restricted to identification and distribution of different phases in the binder system. SEM/EDS is also done on polished surfaces for a better identification of phases as described later in this section. 
Figures 10(a) and (b) show the morphology of the reaction products observed on a fracture surface of the iron carbonate binder. The microstructure is heterogeneous, containing angular iron particles, spherical fly ash particles and porous reaction products. Reaction product film formation is observed on the surface of iron particles. Some reaction product formation is noted on the surface of the fly ash particles as well. A few small cracks are also detected. Figures 11(b) show the EDS spectra of the reaction product formed on the surface of the iron particle shown in Figure 11(a). The results indicate that the final reaction product contains iron, calcium, aluminum, and silicon representing an ironoxalate-carbonate complex incorporating silica. This confirms what has been shown in [17] . EDS spectra is also reported for the non-carbonated sample and is shown in Figure 11(d). The microstructure along with the composition (Figure 11(c) and (d)) are significantly different from that of the carbonated system. Large, unreacted iron particles are observed with no detectable reaction product formation on the surface. Only Fe, C and Si are present in EDS spectra. This confirms that no binding product formation occurs in the absence of dissolved $\mathrm{CO}_{2}$.

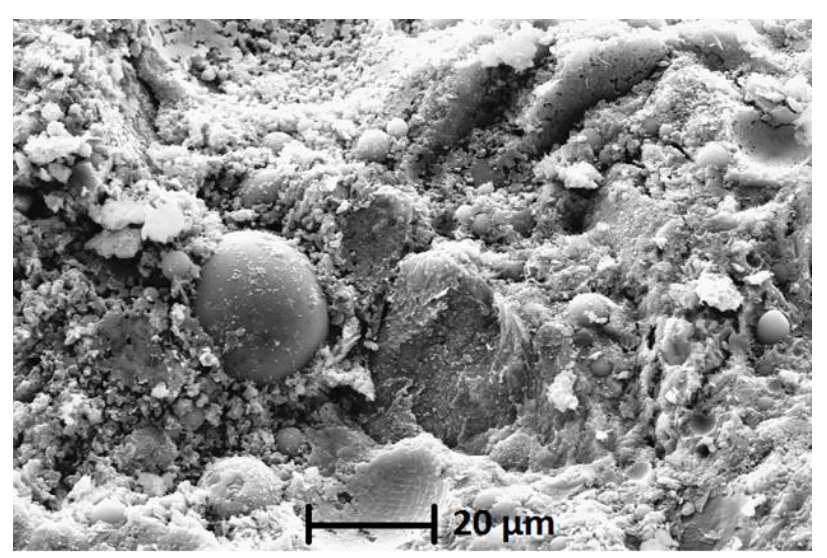

(a)

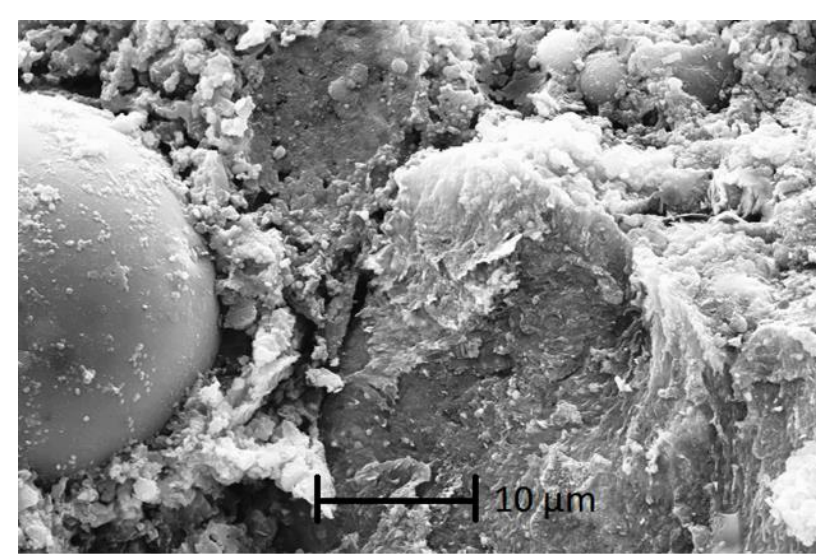

(b)

Figure 10: SE images of iron carbonate binder (Mixture 2) after 4 days of carbonation for and airexposure for 3 days. 


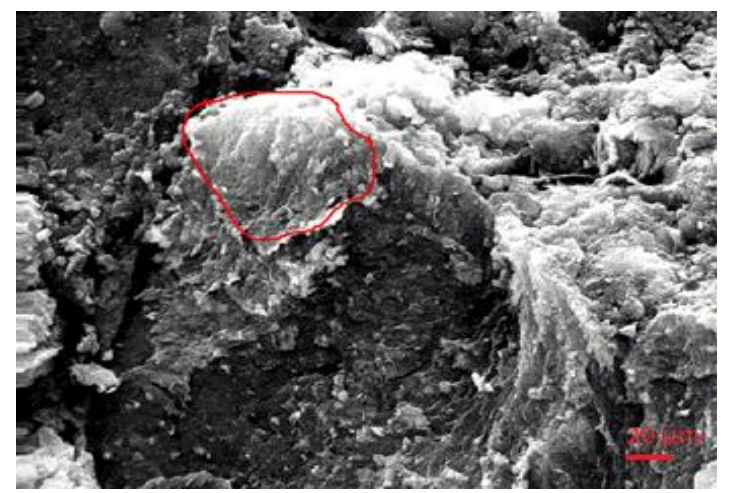

(a)

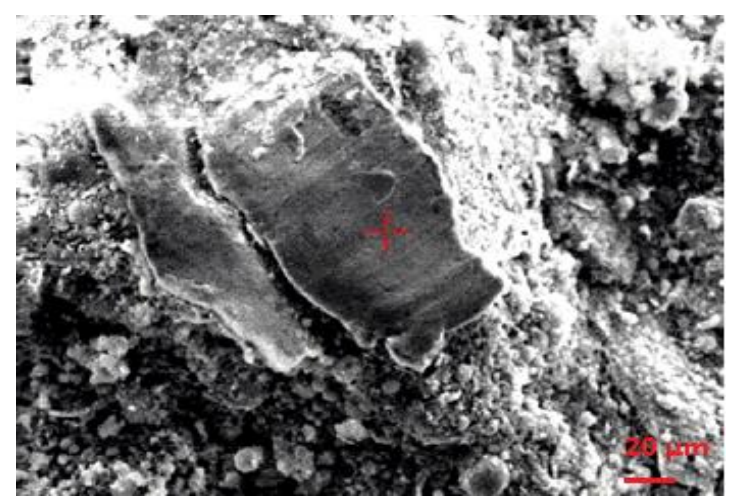

(c)

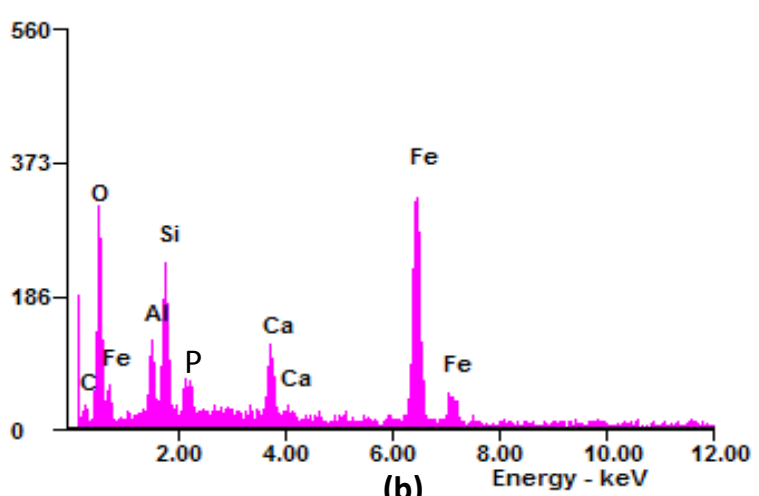

(b)

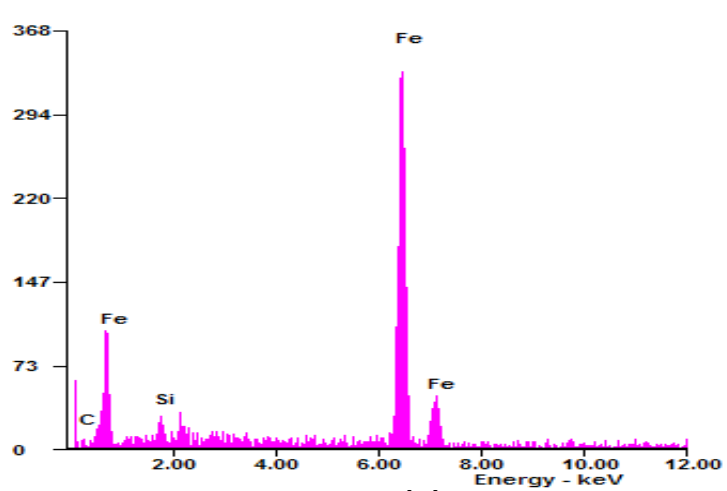

(d)

Figure 11: (a) SE image of Mixture 2 after 4 days of carbonation and 3 days of air-exposure, (b) EDS spectra of area shown in (a); (c) SE image of Mixture 2 after only 3 days of air curing (no carbonation),

(d) EDS spectra at location shown in (d)

Secondary imaging techniques essentially show the morphological nature of the surface of the specimen. The minimum effort to prepare a sample and the ease of interpreting the topographical feature makes secondary imaging techniques very attractive. However, the roughness of the fractures surface which is not representative of the material affects the scattered electron imaging especially the quantitative analysis. A flat surface is required for more accurate compositional analysis. A suitable combination of grinding and polishing has been done on the sample in order to achieve flatness of the surface. Figures 12(a) and (b) show the backscatter electron (BE) images of polished surfaces of the iron carbonate binder along with representative EDS spectra of the points indicated in the images. The elemental composition corresponding to the EDS map of Figure 12(a) indicates that the bright particles are the iron particles. These particles are highly angular as can be seen from the micrograph. The location chosen for EDS analysis shown in Figure 12 (b) is on the relatively dense reaction product 
formed around the iron particle. EDS confirms the presence of iron as the major component, followed by silica, aluminum, carbon, and calcium.

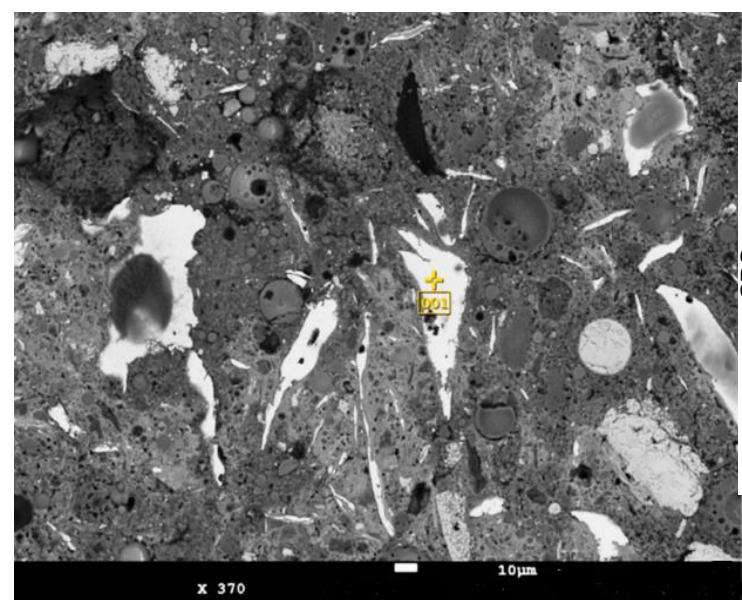

(a)

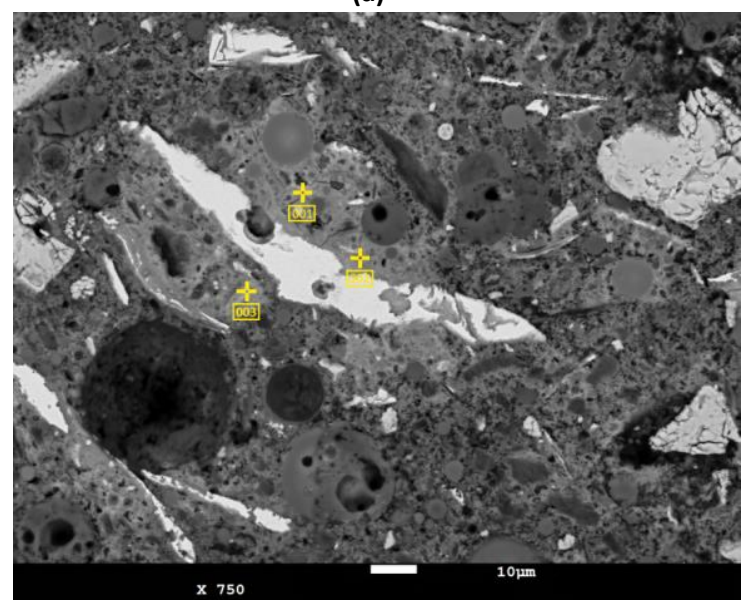

(b)
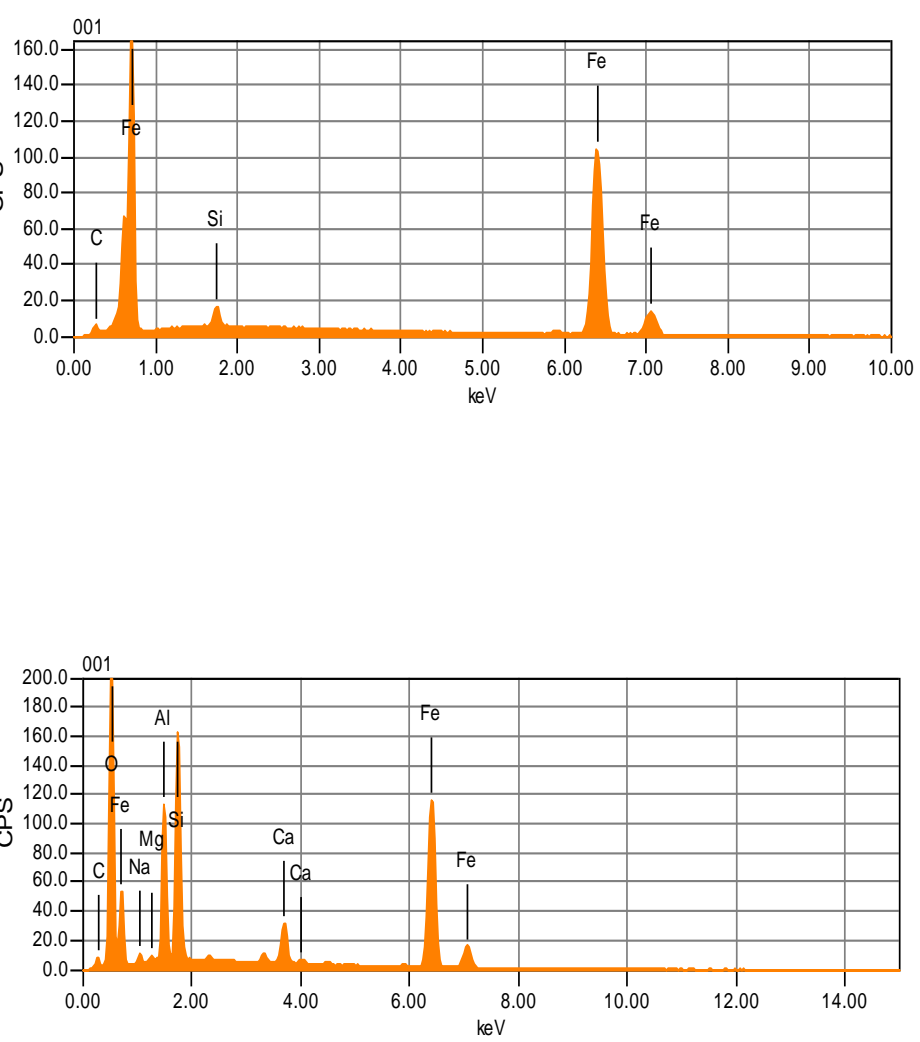

$\mathrm{keV}$

Figure 12: (a) and (b): BE images of Mixture 2 at two different locations after carbonation for 4 days and air curing for 3 days. The representative EDS spectra of the points marked in the micrographs are shown on the right.

Elemental maps were acquired using the EPMA to better understand the spatial distribution of the reaction products. Maps were acquired of iron, silicon, aluminum, calcium, and carbon. The results are shown in Figure 13. The brighter the color, the higher the concentration of the element shown for each map. Iron is observed at locations away from the particles also, aided by the organic dissolution agent. The distribution of carbon is fairly uniform, except in regions occupied by the unreacted iron particles and the fly ash particles where it shows a higher concentration. This would indicate the reaction products which are formed away from the iron particles are also complex iron carbonates, although the 
stoichiometry could be locally different (this is not discounting the presence of carbon from the calcium carbonates added in the matrix also). The circular black regions in the iron elemental map indicate unreacted, rounded fly ash particles which is confirmed by the presence of high concentrations of Si and Al. The distribution of Calcium is also shown to be mostly uniform. This is likely due to the small size (0.7 $\mu \mathrm{m}$ ) of the calcium carbonate (limestone) particles used in the matrix. The utilization of limestone in reaction product formation has also been confirmed through thermo-gravimetric analysis in an earlier study [17].

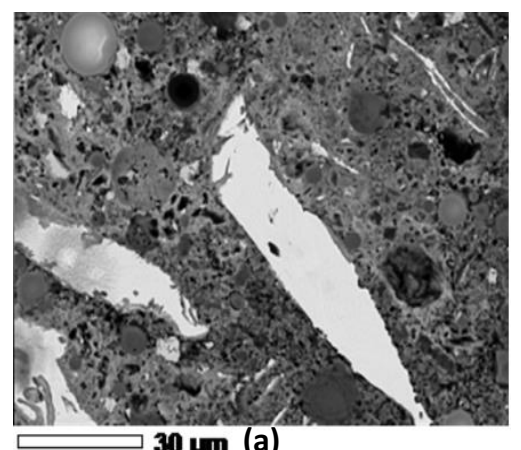

$30 \mathrm{~mm}(\mathrm{a})$
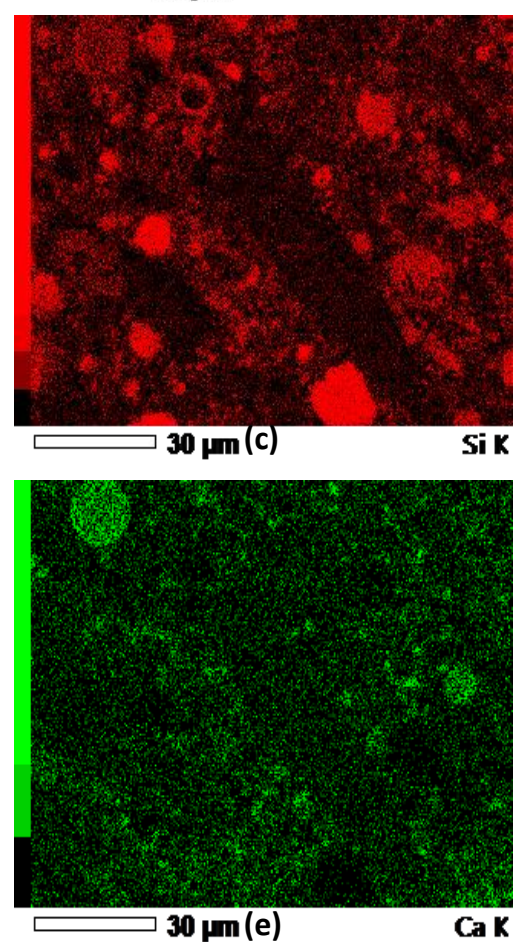
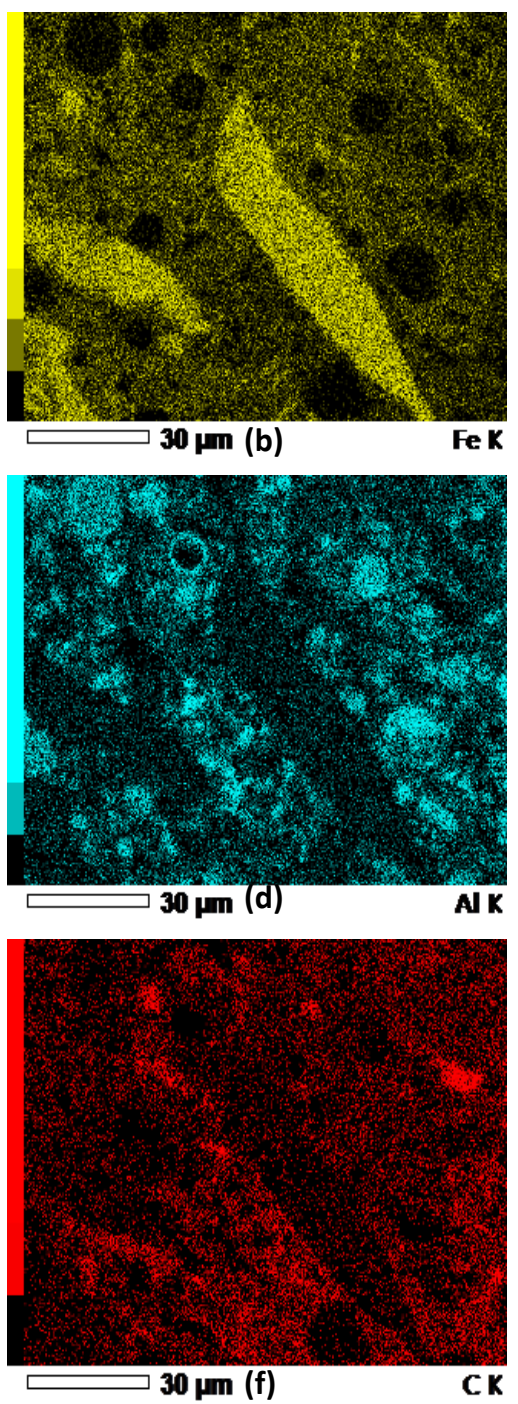

Figure 13: (a) A backscattered electron micrograph of the iron carbonate binder (shown in the upper left) along with EDS elemental maps of: (b) Fe, (c) Si, (d) Al, (e) Ca, and (f) C. 


\subsection{Determination of porosity from BSE images through image analysis}

Image analysis is carried out on BSE micrographs to obtain area fraction of porosity. The images with significant edge effects are discarded and 5 images are thus obtained at different resolutions. The chosen images are processed and analyzed using ImageJ(C), a freely available image analysis software. The grey-scale images are converted to binary image by thresholding to separate the solid and the pore. The threshold limits are chosen based on grey level histogram. Figure 14 (a) shows an original grey scale BSE image and figure 14(b) exhibits the thresholded binary image where black represents pore phase.

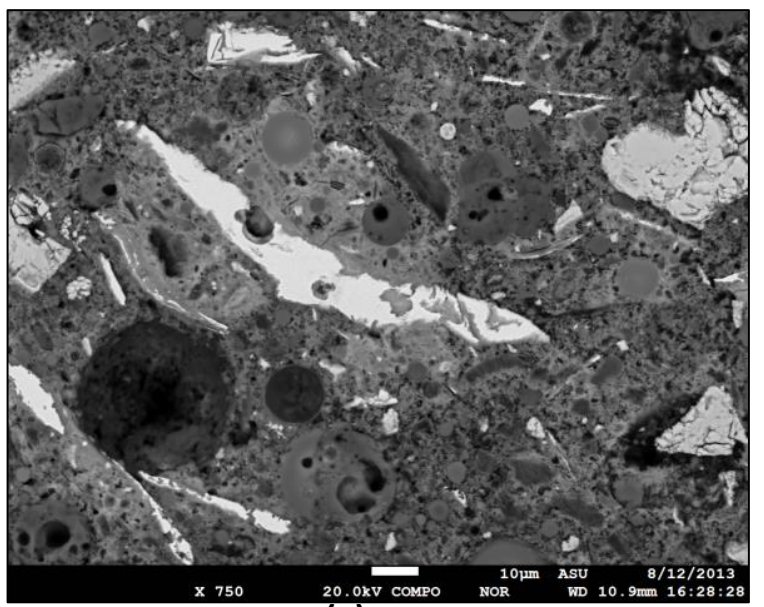

(a)

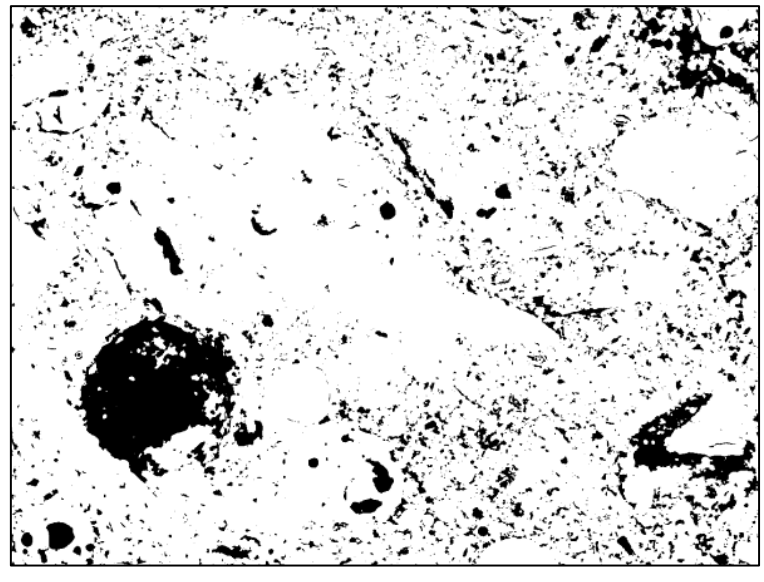

(b)

Figure 14: (a) Original image (Image 1 in table 2); (b) thresholded image

Table 2 reports the area fraction of pores obtained from image analysis at different resolutions. The area fraction of porosity, calculated using image analysis, varies in the range of $5.7 \%-12.15 \%$ which is lower than the volumetric porosity obtained using MIP. It needs to be noted that evaluation of porestructure from BSE micrographs through image analysis requires large number of statistically similar images to obtain reliable results. That's why complete pore-structure features of iron-based binder system are not obtained here through image analysis due to non-availability of good number of statistically similar images at different resolutions. 
Table 2. Porosity from image analysis

\begin{tabular}{|c|c|c|}
\hline Image no & Resolution & Porosity (\%) \\
\hline 1 & $750 \mathrm{X}$ & 12.15 \\
\hline 2 & $550 \mathrm{X}$ & 11.17 \\
\hline 3 & $370 \mathrm{X}$ & 5.667 \\
\hline 4 & $1900 \mathrm{X}$ & 8.281 \\
\hline 5 & $1800 \mathrm{X}$ & 10.099 \\
\hline Average & & 9.4734 \\
\hline
\end{tabular}

\subsection{CONCLUSIONS}

Fundamental characterization of pore- and micro-structure of a novel complex binder system based on the carbonation of metallic iron powder has been discussed in this paper. With metallic iron powder (sourced as a waste/by-product material) used as the major component, minor components such as fly ash, metakaolin, limestone and an organic acid were used in different proportions to impact the reaction product formation as well as rheological characteristics of this binder. The pore- and microstructural properties of the best-performing (based on compressive strength) binder system were reported in this paper.

Increasing the carbonation duration from 1 to 4 days significantly reduced the total pore volume in the iron carbonate binder as determined by MIP. This was in turn reflected in the compressive strength of the binders, while the critical pore size remained relatively unchanged. However, it was observed that the fraction of the larger pores and the average pore size significantly reduced with increasing carbonation duration. A comparison with the pore structure of 28-day cured OPC pastes showed that the overall pore volume was lower in iron carbonated binders, however, the critical pore sizes were larger. The pore structure features (porosity, average pore size, and tortuosity) were used to theoretically determine the water vapor diffusivity through a consideration of Knudsen diffusion, and moisture permeability using a modified version of the Katz-Thompson equation. The implementation of Archie's law to the normalized diffusivity-porosity relationship yielded a cementation factor of around 3 for the iron carbonate binders, which is close to those of many porous engineering materials. The porosities and moisture permeabilities of iron carbonate binders were found to be well correlated by a power-law expression.

Secondary and backscattered imaging revealed many of the important features of the microstructure of this novel binder material. The influence of carbonation on the reaction product formation on iron 
particle surfaces was established. A dense, heterogeneous microstructure was obtained after carbonation. The reaction product analysis using EDS showed the presence of iron, carbon, silicon, aluminum and calcium, indicating that the reaction product is a complex carbonate which was quantified in an earlier study using thermogravimetric analysis.

\subsection{ACKNOWLEDGEMENTS}

The authors sincerely acknowledge the support from National Science Foundation (CMMI: 1353170) towards the conduct of this study. The contents of this paper reflect the views of the authors who are responsible for the facts and accuracy of the data presented herein, and do not necessarily reflect the views and policies of NSF, nor do the contents constitute a standard, specification or a regulation. We gratefully acknowledge the use of facilities within the Laboratory for the Science of Sustainable Infrastructural Materials (LS-SIM) and the LeRoy Eyring Center for Solid State Sciences (LE-CSSS) at Arizona State University. Raw materials were provided by Schuff Steel, Iron Shell LLC, Omya AG, Headwaters Inc., and Burgess Pigments, which are acknowledged.

\subsection{REFERENCES}

[1] Bachu S, Gunter WD, Perkins EH. Aquifer disposal of CO2: Hydrodynamic and mineral trapping. Energy Convers Manag 1994;35:269-79.

[2] Holloway S. An overview of the underground disposal of carbon dioxide. Energy Convers Manag 1997;38, Supplement:S193-S198.

[3] Kaszuba JP, Janecky DR, Snow MG. Carbon dioxide reaction processes in a model brine aquifer at $200{ }^{\circ} \mathrm{C}$ and 200 bars: implications for geologic sequestration of carbon. Appl Geochem 2003;18:1065-80.

[4] Xu T, Apps JA, Pruess K. Numerical simulation of $\mathrm{CO} 2$ disposal by mineral trapping in deep aquifers. Appl Geochem 2004;19:917-36.

[5] Flaathen TK, Gislason SR, Oelkers EH, Sveinbjörnsdóttir ÁE. Chemical evolution of the Mt. Hekla, Iceland, groundwaters: A natural analogue for $\mathrm{CO} 2$ sequestration in basaltic rocks. Appl Geochem 2009;24:463-74.

[6] Gislason SR, Wolff-Boenisch D, Stefansson A, Oelkers EH, Gunnlaugsson E, Sigurdardottir H, et al. Mineral sequestration of carbon dioxide in basalt: A pre-injection overview of the CarbFix project. Int J Greenh Gas Control 2010;4:537-45.

[7] Qafoku O, Kovarik L, Kukkadapu RK, Ilton ES, Arey BW, Tucek J, et al. Fayalite dissolution and siderite formation in water-saturated supercritical CO2. Chem Geol 2012;332-333:124-35.

[8] Klein E, De Lucia M, Kempka T, Kühn M. Evaluation of long-term mineral trapping at the Ketzin pilot site for $\mathrm{CO} 2$ storage: An integrative approach using geochemical modelling and reservoir simulation. Int J Greenh Gas Control 2013;19:720-30.

[9] Xu T, Apps JA, Pruess K, Yamamoto H. Numerical modeling of injection and mineral trapping of $\mathrm{CO} 2$ with H2S and SO2 in a sandstone formation. Chem Geol 2007;242:319-46. 
[10] Naganuma T, Yukimura K, Todaka N, Ajima S. Concept and experimental study for a new enhanced mineral trapping system by means of microbially mediated processes. Energy Procedia 2011;4:5079-84.

[11] Xu T, Apps JA, Pruess K. Mineral sequestration of carbon dioxide in a sandstone-shale system. Chem Geol 2005;217:295-318.

[12] Matter JM, Kelemen PB. Permanent storage of carbon dioxide in geological reservoirs by mineral carbonation. Nat Geosci 2009;2:837-41.

[13] Park A-HA, Jadhav R, Fan L-S. CO2 Mineral Sequestration: Chemically Enhanced Aqueous Carbonation of Serpentine. Can J Chem Eng 2003;81:885-90.

[14] Hobbs DW. The tensile strength of rocks. Int J Rock Mech Min Sci Geomech Abstr 1964;1:385-96.

[15] Hobbs DW. Rock tensile strength and its relationship to a number of alternative measures of rock strength. Int J Rock Mech Min Sci Geomech Abstr 1967;4:115-27.

[16] Herget G, Unrug K. In situ rock strength from triaxial testing. Int J Rock Mech Min Sci Geomech Abstr 1976;13:299-302.

[17] Das S, Souliman B, Stone DA, Neithalath N. Synthesis and Properties of A Novel Structural Binder Utilizing the Chemistry of Iron Carbonation. ACS Appl Mater Interfaces 2014.

[18] Wu SL, Cui ZD, He F, Bai ZQ, Zhu SL, Yang XJ. Characterization of the surface film formed from carbon dioxide corrosion on N80 steel. Mater Lett 2004;58:1076-81.

[19] Nordsveen M, Nešić S, Nyborg R, Stangeland A. A Mechanistic Model for Carbon Dioxide Corrosion of Mild Steel in the Presence of Protective Iron Carbonate Films-Part 1: Theory and Verification. Corrosion 2003;59:443-56.

[20] Nesic S, Postlethwaite J, Olsen S. An Electrochemical Model for Prediction of Corrosion of Mild Steel in Aqueous Carbon Dioxide Solutions. Corrosion 1996;52:280-94.

[21] Villamizar W, Casales M, Martinez L, Chacon-Naca JG, Gonzalez-Rodriguez JG. Effect of chemical structure of hydroxyethyl imidazolines inhibitors on the $\mathrm{CO} 2$ corrosion in water-oil mixtures. J Solid State Electrochem 2008;12:193-201.

[22] Kumar R, Thangaraj A, Bhat RN, Ratnasamy P. Synthesis of iron-silicate analogs of zeolite beta. Zeolites 1990;10:85-9.

[23] Fairén AG, Fernández-Remolar D, Dohm JM, Baker VR, Amils R. Inhibition of carbonate synthesis in acidic oceans on early Mars. Nature 2004;431:423-6.

[24] Moon HY, Kim HS, Choi DS. Relationship between average pore diameter and chloride diffusivity in various concretes. Constr Build Mater 2006;20:725-32.

[25] Ghafari E, Costa H, Júlio E, Portugal A, Durães L. The effect of nanosilica addition on flowability, strength and transport properties of ultra high performance concrete. Mater Des 2014;59:1-9.

[26] Sánchez-Fajardo VM, Torres ME, Moreno AJ. Study of the pore structure of the lightweight concrete block with lapilli as an aggregate to predict the liquid permeability by dielectric spectroscopy. Constr Build Mater 2014;53:225-34.

[27] Carniglia SC. Construction of the tortuosity factor from porosimetry. J Catal 1986;102:401-18.

[28] Scheidegger AE. Physics of flow through porous media. Phys. Flow Porous Media, University of Toronto; 1963.

[29] Plessis JPD, Masliyah JH. Mathematical modelling of flow through consolidated isotropic porous media. Transp Porous Media 1988;3:145-61.

[30] Winslow DN. Advances in Experimental Techniques for Mercury Intrusion Porosimetry. In: Matijević E, Good RJ, editors. Surf. Colloid Sci., Springer US; 1984, p. 259-82.

[31] Giesche H. Mercury Porosimetry: A General (Practical) Overview. Part Part Syst Charact 2006;23:919.

[32] Feldman RF. Pore Structure Damage in Blended Cements Caused by Mercury Intrusion. J Am Ceram Soc 1984;67:30-3. 
[33] Lawrence GP. Stability of Soil Pores During Mercury Intrusion Porosimetry. J Soil Sci 1978;29:299304.

[34] Chindaprasirt P, Jaturapitakkul C, Sinsiri T. Effect of fly ash fineness on compressive strength and pore size of blended cement paste. Cem Concr Compos 2005;27:425-8.

[35] Cook RA, Hover KC. Mercury porosimetry of hardened cement pastes. Cem Concr Res 1999;29:933-43.

[36] Goto S, Roy DM. The effect of w/c ratio and curing temperature on the permeability of hardened cement paste. Cem Concr Res 1981;11:575-9.

[37] Tanaka K, Kurumisawa K. Development of technique for observing pores in hardened cement paste. Cem Concr Res 2002;32:1435-41.

[38] Archie GE. The electrical resistivity log as an aid in determining some reservoir characteristics. Trans AIMe 1942;146:54-62.

[39] Peng S, Hu Q, Hamamoto S. Diffusivity of rocks: Gas diffusion measurements and correlation to porosity and pore size distribution. Water Resour Res 2012;48:W02507.

[40] lii RBE, Watson GM, Mason EA. Gaseous Diffusion in Porous Media at Uniform Pressure. J Chem Phys 1961;35:2076-83.

[41] Gelderblom H, Marín ÁG, Nair H, van Houselt A, Lefferts L, Snoeijer JH, et al. How water droplets evaporate on a superhydrophobic substrate. Phys Rev E 2011;83:026306.

[42] LaManna JM, Kandlikar SG. Determination of effective water vapor diffusion coefficient in pemfC gas diffusion layers. Int J Hydrog Energy 2011;36:5021-9.

[43] Liu Y. Modeling and Simulation of Methane Production from Hydrate Reserves. ProQuest; 2008.

[44] Lide DR. CRC Handbook of Chemistry and Physics, 84th Edition. CRC Press; 2003.

[45] Kast W, Hohenthanner C-R. Mass transfer within the gas-phase of porous media. Int J Heat Mass Transf 2000;43:807-23.

[46] Ataka Y, Kato S, Zhu Q. Evaluation of Effective diffusion coefficient in various building material and absorbents by mercury intrusion porosimetry. J Environ Eng AIJ 2005:15-21.

[47] Swanson BF. A Simple Correlation Between Permeabilities and Mercury Capillary Pressures. J Pet Technol 1981;33.

[48] Stanley K. Analysis of pore throat size and use of the waxman-smits equation to determine ooip in spindle field, Colorado, Society of Petroleum Engineers; 1980.

[49] Katz AJ, Thompson AH. Quantitative prediction of permeability in porous rock. Phys Rev B Condens Matter 1986;34:8179-81.

[50] Katz AJ, Thompson AH. Prediction of rock electrical conductivity from mercury injection measurements. J Geophys Res Solid Earth 1987;92:599-607.

[51] Neithalath N, Sumanasooriya MS, Deo O. Characterizing pore volume, sizes, and connectivity in pervious concretes for permeability prediction. Mater Charact 2010;61:802-13.

[52] Sumanasooriya MS, Neithalath N. Pore structure features of pervious concretes proportioned for desired porosities and their performance prediction. Cem Concr Compos 2011;33:778-87.

[53] Webb PA. An introduction to the physical characterization of materials by mercury intrusion porosimetry with emphasis on reduction and presentation of experimental data. Micromeritics Instrum Corp Norcross Ga 2001. 